\title{
Survival Rates of Endodontically Treated Teeth After Placement of Definitive Coronal Restoration: 8-Year Retrospective Study
}

This article was published in the following Dove Press journal:

Therapeutics and Clinical Risk Management

\author{
Durre Sadaf $\mathbb{D}^{1,2}$ \\ 'Conservative Dentistry Department, \\ College of Dentistry, Qassim University, \\ Qassim, Saudi Arabia; ${ }^{2}$ Graduate Reading, \\ Centre of Evidence-Based Medicine, \\ University of Oxford, Oxford, UK
}

Introduction: Preservation of endodontically treated teeth (ETT) depends upon several patient-related and operator-related factors. The objectives of this study were to assess the effects of different types of coronal restoration and delayed placement on ETT survival.

Methods: Data on dates of root canal treatment (RCT), restoration type, and extraction time of tooth, when applicable, were analyzed for all patients who underwent RCT from 2010 to 2018 at our institution.

Inclusion Criteria: Root canal-treated teeth with complete preoperative and postoperative radiographs; ETT that were restorable and received final permanent coronal restorations; no periodontal disease or crack detected during RCT; and ETT with acceptable RCT quality.

Exclusion Criteria: Patients who did not attend for follow-up, those had incomplete information available about the coronal restoration, and those with periodontally compromised teeth were excluded. ETT that involved any procedural error were also excluded. The teeth were categorized according to whether they underwent definitive coronal restoration 0-14 days, 15-59 days, or 60+ days after RCT. The statistical analysis was performed using SPSS version 25 (IBM Corp., Armonk, NY). The rate of survival of ETT of 8 years was estimated, and the differences between groups were determined after applying Kaplan-Meier statistics and log-rank tests. A multivariate Cox regression test and Wilcoxon (Gehan) statistics were computed to analyze the influence of different variables. A $P$-value $<0.05$ was considered as statistically significant.

Results: The type of restoration, opposing dentition, presence of a post, and dentistry training (year 4 or 5 students) showed significant effects on the survival of ETT $(P \leq 0.000)$. ETT which received crowns was 2.05 times more likely to need extraction than those in which a composite buildup was performed (hazard ratio [HR] 2.05; confidence interval [CI] 1.84-2.29; $P \leq 0.000$ ). All composite buildups were performed within 14 days of completion of RCT. There was a significant correlation between the time of placement of the final coronal restoration and ETT survival $(P \leq 0.000)$. Extraction of ETT was $25 \%$ more likely (HR 0.25 ; CI $0.231-0.277$ ) when the final coronal restoration was placed 15-59 days after completion of RCT and 73\% more likely (HR 0.73; CI 0.655-0.814) when placed after 60 days than when placed at 0-14 days.

Conclusion: Timely placement of the final coronal restoration is found to be the most critical factor affecting the long-term survival of teeth after RCT.

Keywords: dental crown, endodontically treated teeth, root canal therapy, root canal treatment, survival analysis, survival rate

\section{Introduction}

Several clinical studies on the long-term results of root canal treatment (RCT) have been reported. ${ }^{1-5}$ There is evidence showing that RCT performed by undergraduate
Correspondence: Durre Sadaf Email d.ahmad@qu.edu.sa
Therapeutics and Clinical Risk Management 2020:16 |25-131

125

your manuscript in $\square$ 
and graduate students is of acceptable quality. ${ }^{6-8}$ However, the outcome of RCT varies widely according to the clinical procedures, patient selection, final coronal restoration, and techniques used. ${ }^{9,10}$ Coronal and/or root fractures are found to be the most frequent reasons for repair and extraction of teeth after RCT, ${ }^{11-14}$ and post-endodontic restorations have an important role in the survival of ETT. ${ }^{15-19}$

The effects of coronal restoration on the outcome of RCT have been investigated extensively in various clinical studies. ${ }^{16,20-23}$ Although the results of these studies suggest that coronal restorations are important for the success of endodontic therapy, some investigators have questioned their influence. ${ }^{8}$ One author concluded that the quality of obturation is the most critical factor in the success of ETT. ${ }^{24}$ Moreover, the debate continues among dental practitioners about the selection of the final restoration type once RCT is completed. ${ }^{25-28}$

Pirani et al analyzed a 10-year data in an endodontics master's program and found an $85 \%$ success rate of root canal treatment obturated with thermafill and AH Plus sealer. ${ }^{29}$ Prati et al found $80 \%$ survival of ETT in their 20 years recall study with non-endodontic reasons as the main causes of the extraction of root-filled teeth. ${ }^{30}$ Stenhagen et al recently studied the influence of coronal restorations on the survival of ETT and found that the indirect restorations have a significantly higher survival rate when compared to direct restorations. ${ }^{31}$ In a largescale study conducted on the basis of insurance claims data, Yee et al concluded that long-term survival rates of initial root canal treatment are adversely affected by the delayed placement of the final coronal restoration. ${ }^{32}$

Given the significance with regard to final coronal restoration and its effects on the outcome of ETT, we performed this study to investigate the effects of different types of coronal restoration and delayed placement on ETT survival. To our knowledge, there are no long-term data available on the survival of ETT or relevant studies containing a large sample size in the Middle Eastern population.

\section{Materials and Methods}

The study protocol was approved by the Ethical Approval Committee and Dental Research Center of Qassim University, Saudi Arabia (Code \#: ST/48/2018). The study data were collected from the electronic database at the college of Dentistry, Qassim University. All permanent teeth in which nonsurgical RCT was performed in the Department of Endodontics by undergraduate dental students in years 4 or 5 between January 1, 2010, and April 1, 2018, were identified.
The records of patients who came for regular follow-up were then selected, resulting in 4012 ETT for 3863 patients. Identification of patients was maintained as confidential throughout this retrospective study by the allocation of codes against patient file numbers. Informed consent is not required for such studies as guided by the institutional Ethical Approval Committee and Dental Research Center.

The inclusion criteria of this study were as follows: root canal-treated teeth with complete preoperative and postoperative radiographs; ETT that were restorable and received final permanent coronal restorations; no periodontal disease or crack detected during RCT; and ETT with acceptable RCT quality as described by Tronstad et al. ${ }^{33}$ Patients who did not attend for follow-up, those had incomplete information available about the coronal restoration, and those with periodontally compromised teeth were excluded. ETT that involved any procedural error were also excluded.

The following information was collected: patient age and gender, type of tooth (anterior, premolar, or molar), whether or not the tooth under treatment was in the maxilla or mandible, and occluding condition of the opposing dentition (fixed prosthesis, natural teeth, or edentulous/none); start and completion dates of nonsurgical RCT, number of sessions of RCT (single visit or multiple visits), type of coronal restoration (crown or buildup), and if a post was present; date of placement of the coronal restoration; and the date and reason in the event of an extraction.

\section{Crown}

A full-coverage cast restoration that is fabricated in the laboratory to restore missing tooth structure. ${ }^{34}$

\section{Direct Buildup}

A foundation restoration is done chairside that is used to restore sufficient coronal anatomy of lost tooth structure in ETT using direct restorative material. ${ }^{34}$

\section{Criteria to Choose Crown versus Buildup}

With three or four left coronal walls, which means that one marginal ridge is at least preserved, and cavity walls are not undermined, a buildup using direct adhesive restoration can be considered. ${ }^{35}$ ETT with few or undermined coronal walls, coverage with a crown is advised. ${ }^{35}$

When assessing tooth survival, extraction was considered a failure. We considered survival as the existence of ETT by the end of the study period (April 1, 2018). The 
date of the last recall visit was considered as the date of the censor for ETT, i.e., extraction was not performed during the study period.

The statistical analysis was performed using SPSS version 25 (IBM Corp., Armonk, NY). We estimated the rate of survival of ETT of 8-year and determined the differences between groups after applying Kaplan-Meier statistics and log-rank tests. A multivariate Cox regression test and Wilcoxon (Gehan) statistics were computed to analyze the influence of different variables. A $P$-value $<0.05$ was considered as statistically significant.

\section{Results}

\section{Distribution and Characteristics}

As a part of the present retrospective study of 8 years, 4012 teeth from 3863 patients (male, 32.53\%; female, $67.47 \%$ ) with a mean age of 37.27 years were considered for analysis. Of the 4012 teeth studied, 3362 (83.80\%) had full-coverage crowns placed after RCT, and 650 (16.20\%) received composite buildup restorations (Table 1).

\section{Survival Analysis}

In the present study, 2800 teeth (69.79\%) were extracted, and 1212 (30.21\%) exhibited survival until the study period concluded (April 1, 2018). There was a statistically significant difference in the survival rate as a function of patient gender in that the ETT survived in $24.3 \%$ of female patients and in $42.5 \%$ of male patients. Furthermore, $84.61 \%$ of the extracted teeth were in the crown coverage group, and $15.39 \%$ were in the buildup restoration group $(P<0.00$; Figure 1A). Four hundred and ninety-eight teeth $(12.4 \%)$ were extracted because of a crown fracture, 288 (7.2\%) because of a failed restoration, and 2014 (50.2\%) for endodontic reasons (Table 2).

The Kaplan-Meier method was used for survival analysis of the clinical variables, and the significance was assessed by applying the log-rank test. The variables with prognostic worth that were included in univariate analysis were restoration type once RCT was completed, dental arch, gender, condition of the opposing dentition, year of student (4 or 5), number of visits for completion of RCT (one visit or more than one visit) and if a post was placed. Figure 1B demonstrates the survival curve of Kaplan-Meier for the different restoration types. Eight-year ETT survival was 79.5\% no matter what type of restoration was placed once RCT was completed. The survival rate of 8 -year after completion of RCT was $76 \%$
Table I Characteristics and Distribution of Endodontically Treated Teeth

\begin{tabular}{|c|c|c|c|}
\hline & \multicolumn{2}{|l|}{$\mathbf{N}(\%)$} & \multirow[t]{2}{*}{ P-value* } \\
\hline & $\begin{array}{l}\text { Crown } \\
n=3362 \\
(83.8 \%)\end{array}$ & $\begin{array}{l}\text { Buildup } \\
\text { Restoration } \\
n=650 \\
(16.2 \%)\end{array}$ & \\
\hline \multicolumn{4}{|l|}{ Gender } \\
\hline Male & $|I 4|(33.9)$ & $164(25.2)$ & $<0.00$ \\
\hline Female & $221(66.1)$ & $486(74.8)$ & \\
\hline \multicolumn{4}{|l|}{ Type of tooth } \\
\hline Molar & I $484(44.1)$ & $164(25.2)$ & \\
\hline Premolar & $1055(31.4)$ & $0(0)$ & \\
\hline Anterior & $823(24.5)$ & $486(74.8)$ & $<0.00$ \\
\hline \multicolumn{4}{|l|}{ Dental Arch } \\
\hline Maxillary & I586 (47.2) & $138(2 \mid .2)$ & $<0.00$ \\
\hline Mandibular & $1776(52.8)$ & $512(78.8)$ & \\
\hline \multicolumn{4}{|l|}{$\begin{array}{l}\text { Opposing } \\
\text { dentition }\end{array}$} \\
\hline Natural & $2094(62.3)$ & $567(87.2)$ & $<0.00$ \\
\hline Fixed Prosthetic & $989(29.4)$ & $83(12.8)$ & \\
\hline None & $279(8.3)$ & $0(0)$ & \\
\hline \multicolumn{4}{|l|}{ Visits } \\
\hline Single & $788(23.4)$ & $138(2 \mid .2)$ & 0.221 \\
\hline Multiple & $2574(76.6)$ & $5 \mid 2(78.8)$ & \\
\hline \multicolumn{4}{|l|}{ Post } \\
\hline Present & $1243(37)$ & $0(0)$ & $<0.00$ \\
\hline Absent & $2119(63)$ & $650(100)$ & \\
\hline \multicolumn{4}{|l|}{$\begin{array}{l}\text { Year of dental } \\
\text { student }\end{array}$} \\
\hline $4^{\text {th }}$ year & 87I (25.9) & 301 (46.3) & $<0.00$ \\
\hline $5^{\text {th }}$ year & $249 \mid(74.1)$ & $349(53.7)$ & \\
\hline
\end{tabular}

Note: $* p=0.05$ (Chi-square test).

when the final restoration included a crown and $83 \%$ when it included a composite buildup (Table 3).

For further analysis of the effects of type and time of placement of the final coronal restoration after RCT, we calculated the hazard ratio (HR) for each chosen variable. A Cox proportional hazards model showed that ETT, when restored with buildup restorations using composite, was 2.05 times less prone to extraction (HR 2.05; confidence interval [CI] 1.84-2.29; $P \leq$ 0.000). The mean time until the final restoration was 1.82 months. All composite buildups were performed on the day that the RCT was completed. In total 1425 $(43 \%)$ of porcelain fused to metal (PFM) crowns were placed within 2 weeks of completion of RCT, 586 

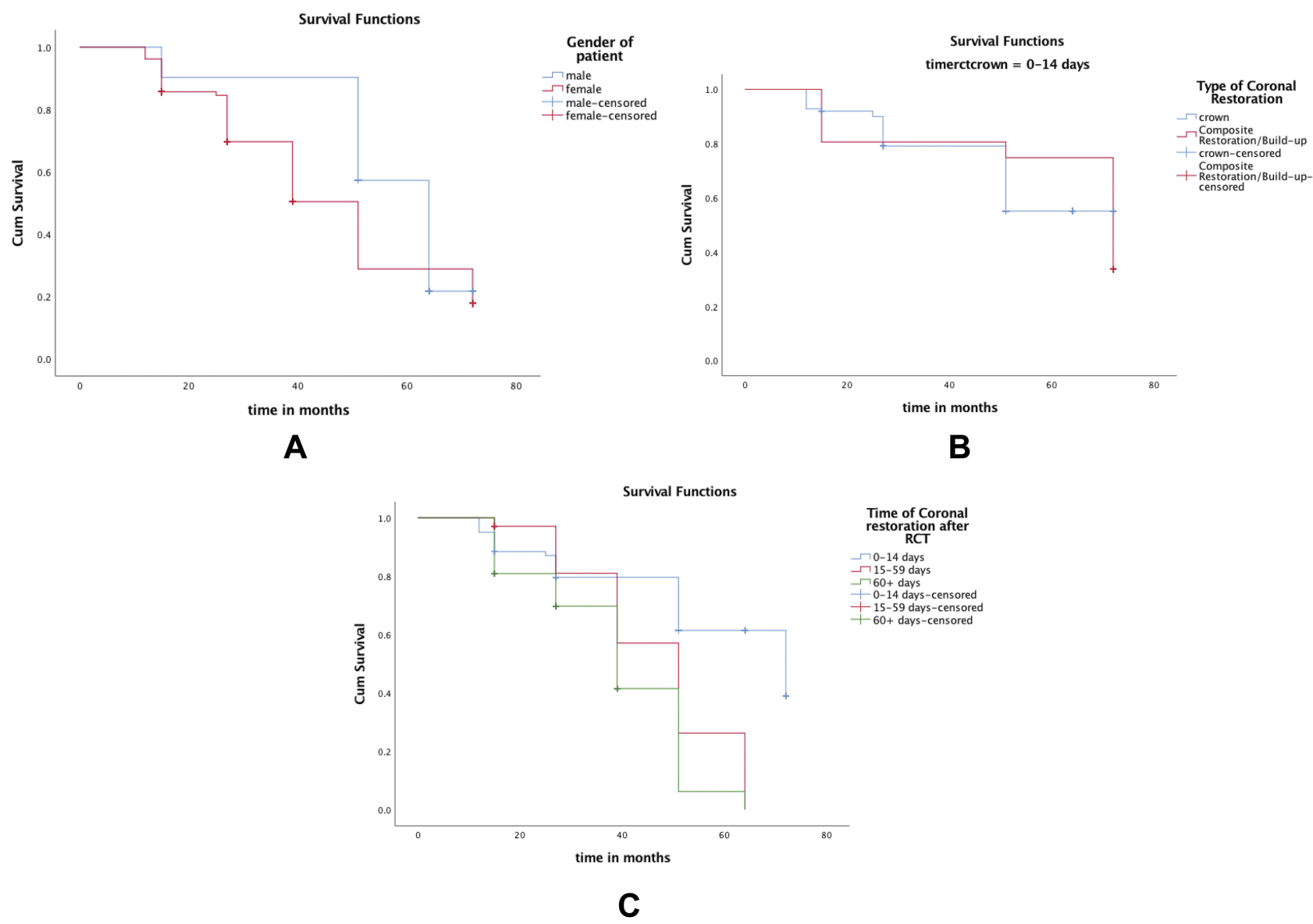

Figure I (A) Estimated survival function of ETT as a function of individuals' gender (males $n=1305$ : females $n=2702$ ). (B) Estimated survival function of ETT as a function of type of restoration (composite buildup $n=650$; Crown $n=3362$ ). (C) Kaplan-Meier survival curve as a function of time of placement of the final coronal restoration. The 8-year survival of ETT which received final coronal restoration from 0 to 14 days was $72 \%$, from 15 to 59 days was $51 \%$ and after $60+$ days was $39 \%$.

(17.7\%) within 15-59 days, and 1297 (96.4\%) after more than 60 days.

We also analyzed ETT survival according to the timing of the final coronal restoration using the Kaplan-Meier statistical approach; the statistical significance was assessed using the log-rank and Gehan-Wilcoxon tests. Figure 1C shows the Kaplan-Meier curve of survival for timing of placement of final coronal restoration after RCT. The life tables showed a significant correlation between crown placement timing once RCT was completed and ETT survival $(P \leq 0.000)$.

Table 2 Causes of Extraction of Endodontically Treated Teeth

\begin{tabular}{|l|l|}
\hline Causes of Extraction & n (\%) \\
\hline Fracture of the crown & $498(12.4)$ \\
Causes related to prosthetics (failure of restoration) & $288(7.2)$ \\
Causes related to endodontics (a vertically fractured root) & $2014(50.2)$ \\
\hline
\end{tabular}

The Cox proportional hazards model showed that ETT in which the final coronal restorations were placed between 15 and 59 days were $25 \%$ more likely to be extracted (HR 0.25; CI 0.231-0.277) and those in which restorations were placed after 60 days were $73 \%$ more likely to be extracted (HR 0.73; CI $0.655-0.814, P \leq 0.00$ ).

This study was conducted at an undergraduate dental institution, so the ETT survival rate was compared between those performed by year 4 students and those performed by year 5 students. The Cox proportional hazards model showed that the year 4 students were 1.13 times more likely than year 5 students to provide a final coronal restoration on an ETT that was extracted later on (HR 1.13; CI 1.04-1.22, $P=0.004$ ).

\section{Discussion}

As far as our knowledge is concerned, the present study, which included 4012 teeth, is the first to explore the impact of timing of the final coronal restoration once RCT is 
Table 3 Eight-Year Survival Table for Endodontically Treated Teeth

\begin{tabular}{|c|c|c|}
\hline Variable & $\begin{array}{l}\text { 8-Year Survival } \\
\text { Based on Life Table }\end{array}$ & P-value* \\
\hline $\begin{array}{l}\text { Type of restoration after } \\
\text { RCT } \\
\text { Full coverage cast } \\
\text { restoration (crown) } \\
\text { Buildup using composite }\end{array}$ & $\begin{array}{l}76 \\
83\end{array}$ & $<0.000$ \\
\hline $\begin{array}{l}\text { Gender } \\
\text { Male } \\
\text { Female }\end{array}$ & $\begin{array}{l}78 \\
73\end{array}$ & $<0.000$ \\
\hline $\begin{array}{l}\text { Dental arch } \\
\text { Maxillary } \\
\text { Mandibular }\end{array}$ & $\begin{array}{l}68 \\
75\end{array}$ & $<0.000$ \\
\hline $\begin{array}{l}\text { Condition of opposing teeth } \\
\text { Natural dentition } \\
\text { Fixed Prosthesis } \\
\text { Edentulous/None }\end{array}$ & $\begin{array}{l}72.8 \\
64.3 \\
62\end{array}$ & $<0.000$ \\
\hline $\begin{array}{l}\text { Visits } \\
\text { Single } \\
\text { Multiple }\end{array}$ & $\begin{array}{l}73.5 \\
73.6\end{array}$ & $<0.000$ \\
\hline $\begin{array}{l}\text { Post } \\
\text { Yes } \\
\text { No }\end{array}$ & $\begin{array}{l}78.6 \\
74.3\end{array}$ & $<0.000$ \\
\hline $\begin{array}{l}\text { Year of dental student } \\
4^{\text {th }} \\
5^{\text {th }}\end{array}$ & $\begin{array}{l}75 \\
72.6\end{array}$ & $<0.000$ \\
\hline $\begin{array}{l}\text { Time of coronal restoration } \\
\text { after RCT, days } \\
0-14 \\
15-59 \\
60+\end{array}$ & $\begin{array}{l}51 \\
74.9 \\
96\end{array}$ & $<0.000$ \\
\hline
\end{tabular}

Note: $* P=0.05$ (Gehan-Wilcoxon test).

completed on ETT survival rates in the Middle Eastern population. The study was conducted in the central province of Saudi Arabia, which is a heavily populated region. Since this study was conducted in free of charge government undergraduate dental institute, which has a very large turnover of patients, the results of this study represent the possible generalization in the population of this region. We found that the factors which are related to patients, such as gender, and factors that are related to teeth, such as whether the ETT was in the maxillary or mandibular arch, the opposing dentition, and the tooth type, had significant effects on ETT survival. These findings are consistent with those of Lee et $\mathrm{al}^{36}$ who found that both patient- related and tooth-related factors had a significant effect on tooth survival and periapical healing, but are in contrast with those of previous studies that found these factors to have no effect on survival of ETT. ${ }^{37-40}$

However, this study confirms the findings of previous studies that demonstrated an association of tooth survival after RCT with the condition of the opposing dentition. ${ }^{41,42}$

We also explored what is the effect of restoration type once RCT was completed and found that the 8-year survival rate was $83 \%$ with a core buildup restoration and $73 \%$ with a crown. The type of restoration had a significant effect on ETT survival. It is noteworthy that all core buildups were placed on the same day of completion of RCT, which was not the case in ETT that received a crown as their final coronal restoration. In total, $96.4 \%$ of crown placements were done after more than 60 days once RCT was completed. This finding is similar to Stenhagen et al who found in their student-based study that the time from completion of RCT to the placement of a final coronal restoration was significantly longer in cases where indirect restorations were placed when compared to direct restorations. ${ }^{31}$ Early placement of final coronal restoration increases the longevity of ETT..$^{12,20,43,44}$ Although it was not clear in this study if the longevity of ETT that underwent early final coronal restoration is mainly because of reinforcement of the tooth structure or prevention of microleakage, the main reason for the extraction of ETT was a vertical root fracture $(50.2 \%)$. This finding is in agreement with Prati et al who found root fracture as the most frequent reason for the extraction of ETT in their 20year recall study. ${ }^{30}$ Pirani et al found in their 10-year data for patients treated in a postgraduate endodontic program that loss of ETT is most frequently due to non-restorable fractures of tooth root structure. ${ }^{29}$ This finding also suggests that a delay in the final coronal restoration, i.e., placement of a crown, could be a contributing factor. $^{10,45-47}$ This finding is in contrast with a report by Pratt et al who found crown fractures to be the most common reason for tooth loss after RCT. ${ }^{39}$ The results of the present study advance the work done by Pratt et al in that it was performed in an undergraduate dental college with a large sample size whereas their study was performed in a postgraduate endodontic training centre. Furthermore, the present study is the first of its type to be performed in the Middle Eastern population.

In this study, teeth that were treated by year 4 students were more likely to be extracted later on than those treated 
by year 5 students, possibly because of the better training and competency levels achieved in year $5 .^{48,49}$

We found that the presence of a post affects the survival of ETT, which is in agreement with the data from a metaanalysis performed by Zhou and Wang. ${ }^{50}$ The role of a post in the survival of ETT is debatable because of the many other factors involved, such as the presence of ferrule and the type and the quality placement of the post. ${ }^{44,51-53}$

\section{Conclusion}

This study was performed in the setting of a government undergraduate dental college, which may explain the delay in crown placement in ETT. Within the limitations of this study, it can be concluded that crown placement should not be delayed because of the potentially significant negative impact on ETT survival. It should be noted that there can be other preoperative and intraoperative factors specifically related to the status of the pulp and peri-radicular tissue of the tooth that may affect the serviceability of ETT at follow-up. ${ }^{23,54}$ Nonetheless, this study highlights the effects of placement timing of the final coronal restoration on ETT survival. We recommend that the role of the other above-mentioned variables in ETT survival should be assessed in further randomized controlled clinical trials.

\section{Disclosure}

The author reports no conflicts of interest in this work.

\section{References}

1. Ng YL, Mann V, Rahbaran S, Lewsey J, Gulabivala K. Outcome of primary root canal treatment: systematic review of the literature - part 1. Effects of study characteristics on probability of success. Int Endod J. 2007;40(12):921-939. doi:10.1111/j.1365-2591.2007.01322.x

2. Pirani C, Chersoni S, Montebugnoli L, Prati C. Long-term outcome of non-surgical root canal treatment: a retrospective analysis. Odontology. 2015;103(2):185-193. doi:10.1007/s10266-014-0159-0

3. Sjogren U, Hagglund B, Sundqvist G, Wing K. Factors affecting the long-term results of endodontic treatment. $J$ Endod. 1990;16 (10):498-504. doi:10.1016/S0099-2399(07)80180-4

4. Stoll R, Betke K, Stachniss V. The influence of different factors on the survival of root canal fillings: a 10 -year retrospective study. $J$ Endod. 2005;31(11):783-790. doi:10.1097/01.don.0000158229.43298.a9

5. Iqbal MK, Kim S. For teeth requiring endodontic treatment, what are the differences in outcomes of restored endodontically treated teeth compared to implant-supported restorations? Int J Oral Maxillofac Implants. 2007;22 Suppl:96-116.

6. Alhablain EA, Durre S, Ahmad MZ, Alqanass BS. Quality of root canal therapy (RCT) performed by the undergraduate students at the Qassim University, Kingdom of Saudi Arabia (KSA). Medical Forum Monthly. 2018;29(6):80-84.

7. Costa GM, Santos Soares SM, Pelli Paiva PC, et al. Factors affecting the periapical status of root-filled canals: a cross-sectional study at the undergraduate level. Int J Dent. 2017;2017:7413204. doi:10.1155/ $2017 / 7413204$
8. Craveiro MA, Fontana CE, de Martin AS, Bueno CE. Influence of coronal restoration and root canal filling quality on periapical status: clinical and radiographic evaluation. J Endod. 2015;41(6):836-840. doi:10.1016/j.joen.2015.02.017

9. Imura N, Pinheiro ET, Gomes BP, Zaia AA, Ferraz CC, Souza-Filho FJ. The outcome of endodontic treatment: a retrospective study of 2000 cases performed by a specialist. J Endod. 2007;33 (11):1278-1282. doi:10.1016/j.joen.2007.07.018

10. Sequeira-Byron P, Fedorowicz Z, Carter B, Nasser M, Alrowaili EF. Single crowns versus conventional fillings for the restoration of root-filled teeth. Cochrane Database Syst Rev. 2015;9:Cd009109.

11. Chugal NM, Clive JM, Spangberg LS. A prognostic model for assessment of the outcome of endodontic treatment: effect of biologic and diagnostic variables. Oral Surg Oral Med Oral Pathol Oral Radiol Endod. 2001;91(3):342-352. doi:10.1067/moe.2001.113106

12. Gomez-Polo M, Llido B, Rivero A, Del Rio J, Celemin A. A 10-year retrospective study of the survival rate of teeth restored with metal prefabricated posts versus cast metal posts and cores. J Dent. 2010;38 (11):916-920. doi:10.1016/j.jdent.2010.08.006

13. Hansen EK, Asmussen E, Christiansen NC. In vivo fractures of endodontically treated posterior teeth restored with amalgam. Endod Dent Traumatol. 1990;6(2):49-55. doi:10.1111/j.1600-9657.1990.tb0 0389.x

14. Zadik Y, Sandler V, Bechor R, Salehrabi R. Analysis of factors related to extraction of endodontically treated teeth. Oral Surg Oral Med Oral Pathol Oral Radiol Endod. 2008;106(5):e31-e35. doi:10.1016/j.tripleo.2008.06.017

15. Fransson H, Dawson VS, Frisk F, Bjorndal L, EndoReCo KT. Survival of root-filled teeth in the Swedish adult population. J Endod. 2016;42(2):216-220. doi:10.1016/j.joen.2015.11.008

16. Gillen BM, Looney SW, Gu LS, et al. Impact of the quality of coronal restoration versus the quality of root canal fillings on success of root canal treatment: a systematic review and meta-analysis. J Endod. 2011;37(7):895-902. doi:10.1016/j.joen.20 11.04.002

17. Petersson K, Fransson H, Wolf E, Hakansson J. Twenty-year follow-up of root filled teeth in a Swedish population receiving high-cost dental care. Int Endod J. 2016;49(7):636-645. doi:10.11 11/iej.2016.49.issue-7

18. Skupien JA, Opdam N, Winnen R, et al. A practice-based study on the survival of restored endodontically treated teeth. $J$ Endod. 2013;39(11):1335-1340. doi:10.1016/j.joen.2013.06.028

19. Tang W, Wu Y, Smales RJ. Identifying and reducing risks for potential fractures in endodontically treated teeth. J Endod. 2010;36 (4):609-617. doi:10.1016/j.joen.2009.12.002

20. Ahmad MZ, Durre S. Effects of waiting time for definitive restorations after completion of root canal treatment (RCT). Medical Forum Monthly. 2018;29(6):106-108.

21. Ray HA, Trope M. Periapical status of endodontically treated teeth in relation to the technical quality of the root filling and the coronal restoration. Int Endod J. 1995;28(1):12-18. doi:10.1111/iej.1995.28. issue-1

22. Salehrabi R, Rotstein I. Endodontic treatment outcomes in a large patient population in the USA: an epidemiological study. $J$ Endod. 2004;30(12):846-850. doi:10.1097/01.don.0000145031.04236.ca

23. Siqueira JF Jr., Rocas IN, Ricucci D, Hulsmann M. Causes and management of post-treatment apical periodontitis. $\mathrm{Br}$ Dent $\mathrm{J}$. 2014;216(6):305-312. doi:10.1038/sj.bdj.2014.200

24. Siqueira JF Jr., Rocas IN, Alves FR, Campos LC. Periradicular status related to the quality of coronal restorations and root canal fillings in a Brazilian population. Oral Surg Oral Med Oral Pathol Oral Radiol Endod. 2005;100(3):369-374. doi:10.1016/j.tripleo. 2005.03.029

25. Aquilino SA, Caplan DJ. Relationship between crown placement and the survival of endodontically treated teeth. J Prosthet Dent. 2002;87 (3):256-263. doi:10.1067/mpr.2002.122014 
26. Khullar P, Raisingani D, Gupta S, Khatri RK. A survey report on effect of root canal fillings and coronal restorations on the periapical status of endodontically treated teeth in a selected group of population. Int $J$ Clin Pediatric Dent. 2013;6(2):89-94. doi:10.5005/jp-journals-10005-1196

27. Pedro FM, Marques A, Pereira TM, et al. Status of endodontic treatment and the correlations to the quality of root canal filling and coronal restoration. J Contemp Dent Pract. 2016;17(10):830-836. doi:10.5005/jp-journals-10024-1939

28. Safavi KE, Dowden WE, Langeland K. Influence of delayed coronal permanent restoration on endodontic prognosis. Endod Dent Traumatol. 1987;3(4):187-191. doi:10.1111/j.1600-9657.1987.tb00622.x

29. Pirani C, Zamparini F, Peters OA, et al. The fate of root canals obturated with Thermafil: 10-year data for patients treated in a master's program. Clin Oral Investig. 2019;23(8):3367-3377. doi:10.1007/s00784-018-2756-8

30. Prati C, Pirani C, Zamparini F, Gatto MR, Gandolfi MG. A 20-year historical prospective cohort study of root canal treatments. A Multilevel Analysis. Int Endod J. 2018;51(9):955-968. doi:10. 1111/iej.12908

31. Stenhagen S, Skeie H, Bardsen A, Laegreid T. Influence of the coronal restoration on the outcome of endodontically treated teeth. Acta Odontol Scand. 2019;1-6. doi:10.1080/00016357.2019.1640390

32. Yee K, Bhagavatula P, Stover S, et al. Survival rates of teeth with primary endodontic treatment after core/post and crown placement. J Endod. 2018;44(2):220-225. doi:10.1016/j.joen.2017.08.034

33. Tronstad L, Asbjornsen K, Doving L, Pedersen I, Eriksen HM. Influence of coronal restorations on the periapical health of endodontically treated teeth. Endod Dent Traumatol. 2000;16(5):218-221. doi:10.1034/j.1600-9657.2000.016005218.x

34. The glossary of prosthodontic terms: ninth edition. J Prosth Dent. 2017;117(5):e1-e105. doi:10.1016/j.prosdent.2016.12.001

35. Atlas A, Grandini S, Martignoni M. Evidence-based treatment planning for the restoration of endodontically treated single teeth: importance of coronal seal, post vs no post, and indirect vs direct restoration. Quintessence Int (Berl). 2019;50(10):772-781. doi:10.32 90/j.qi.a43235

36. Lee AH, Cheung GS, Wong MC. Long-term outcome of primary non-surgical root canal treatment. Clin Oral Investig. 2012;16 (6):1607-1617. doi:10.1007/s00784-011-0664-2

37. Dammaschke T, Steven D, Kaup M, Ott KH. Long-term survival of root-canal-treated teeth: a retrospective study over 10 years. J Endod. 2003;29(10):638-643. doi:10.1097/00004770-200310000-00006

38. Nagasiri R, Chitmongkolsuk S. Long-term survival of endodontically treated molars without crown coverage: a retrospective cohort study. J Prosthet Dent. 2005;93(2):164-170. doi:10.1016/j.prosdent.20 04.11.001

39. Pratt I, Aminoshariae A, Montagnese TA, Williams KA, Khalighinejad N, Mickel A. Eight-year retrospective study of the critical time lapse between root canal completion and crown placement: its influence on the survival of endodontically treated teeth. J Endod. 2016;42(11):1598-1603. doi:10.1016/j.joen.2016.08.006
40. Tan L, Chen NN, Poon CY, Wong HB. Survival of root filled cracked teeth in a tertiary institution. Int Endod J. 2006;39(11):886-889. doi:10.1111/iej.2006.39.issue-11

41. Caplan DJ, Weintraub JA. Factors related to loss of root canal filled teeth. J Public Health Dent. 1997;57(1):31-39. doi:10.1111/ jphd.1997.57.issue-1

42. Shinogaya T, Bakke M, Thomsen CE, Vilmann A, Sodeyama A, Matsumoto M. Effects of ethnicity, gender and age on clenching force and load distribution. Clin Oral Investig. 2001;5(1):63-68. doi:10.1007/s007840000099

43. Hamedy R, Shakiba B, Fayazi S, Pak JG, White SN. Patient-centered endodontic outcomes: a narrative review. Iran Endod J. 2013;8 (4):197-204.

44. Naumann M, Schmitter M, Frankenberger R, Krastl G. "Ferrule Comes First. Post is second!" Fake news and alternative facts? A systematic review. J Endod. 2018;44(2):212-219. doi:10.1016/j. joen.2017.09.020

45. Fedorowicz Z, Carter B, de Souza RF, Chaves CA, Nasser M, Sequeira-Byron P. Single crowns versus conventional fillings for the restoration of root filled teeth. Cochrane Database Syst Rev. 2012;5:Cd009109.

46. Saunders WP, Saunders EM. Coronal leakage as a cause of failure in root-canal therapy: a review. Endod Dent Traumatol. 1994;10 (3):105-108. doi:10.1111/j.1600-9657.1994.tb00533.x

47. Stavropoulou AF, Koidis PT. A systematic review of single crowns on endodontically treated teeth. J Dent. 2007;35(10):761-767. doi:10.1016/j.jdent.2007.07.004

48. Baaij A, Ozok AR. Method of teaching undergraduate students to perform root canal treatment: it's influence on the quality of root fillings. Eur J Dent Educ. 2018;22(2):e221-e7. doi:10.1111/ eje.2018.22.issue-2

49. Ribeiro DM, Reus JC, Felippe WT, et al. Technical quality of root canal treatment performed by undergraduate students using hand instrumentation: a meta-analysis. Int Endod J. 2018;51(3):269-283. doi:10.1111/iej.2018.51.issue-3

50. Zhou L, Wang Q. Comparison of fracture resistance between cast posts and fiber posts: a meta-analysis of literature. J Endod. 2013;39 (1):11-15. doi:10.1016/j.joen.2012.09.026

51. Hunter AJ, Hunter AR. The treatment of endodontically treated teeth. Curr Opin Dent. 1991;1(2):199-205.

52. Juloski J, Radovic I, Goracci C, Vulicevic ZR, Ferrari M. Ferrule effect: a literature review. J Endod. 2012;38(1):11-19. doi:10.1016/j. joen.2011.09.024

53. Tortopidis D, Papa P, Menexes G, Koidis P. Attitudes of dentists regarding the restoration of root canal treated teeth: a survey in Greece. Int Dent J. 2010;60(5):336-342.

54. Pereira RS, Rodrigues VAA, Furtado WT, Gueiros S, Pereira GS, Avila-Campos MJ. Microbial analysis of root canal and periradicular lesion associated to teeth with endodontic failure. Anaerobe. 2017;48:12-18. doi:10.1016/j.anaerobe.2017.06.016
Therapeutics and Clinical Risk Management

\section{Publish your work in this journal}

Therapeutics and Clinical Risk Management is an international, peerreviewed journal of clinical therapeutics and risk management, focusing on concise rapid reporting of clinical studies in all therapeutic areas, outcomes, safety, and programs for the effective, safe, and sustained use of medicines. This journal is indexed on PubMed Central, CAS,
EMBase, Scopus and the Elsevier Bibliographic databases. The manuscript management system is completely online and includes a very quick and fair peer-review system, which is all easy to use. Visit http://www.dovepress.com/testimonials.php to read real quotes from published authors. 